\title{
O ALTEAMENTO VOCÁLICO /O/ [U] EM POSIÇÃO PRETÔNICA NA ZONA RURAL DO MUNICÍPIO DE BAIÃO-PARÁ
}

\author{
VOCAL HIGHMENT /O/ [U] IN A PRETONIC POSITION IN THE RURAL \\ AREA OF THE MUNICIPALITY OF BAIÃO-PARÁ
}

\author{
Raquel Maria da Silva Costa Furtado ${ }^{1}$ \\ Natane Gaia da Silva Lemos ${ }^{2}$

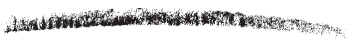

\begin{abstract}
RESUMO
O presente trabalho trata sobre o fenômeno de alteamento vocálico da média alta posterior /o/ em posição pretônica no português falado na zona rural do município de Baião-PA. Objetiva analisar o papel de fatores linguísticos e sociais (sexo, faixa etária e escolaridade) na motivação do comportamento variável de $/ \mathrm{o} / \sim[\mathrm{u}]$. O corpus da pesquisa envolve uma amostra de 12 participantes, estratificados por: faixa etária (de 15 a 25 anos, 25 a 45 anos, e acima de 46 anos); sexo (masculino e feminino); e escolaridade (Ensino Fundamental e Superior). Dos 12 falantes obtivemos um total de 400 dados de fala, os quais foram tratados no Goldvarb X, e analisados de acordo com os pressupostos teórico-metodológicos da Sociolinguística Variacionista (WEINREICH; LABOV; HERZOG, 2006). Os resultados apontaram o alteamento de /o/ como variante de menor ocorrência na fala dos baionenses, com baixa frequência de uso, $33 \%$ e peso relativo 0.32 , e a manutenção de /o/ como [o] como variante de maior ocorrência, $67 \%$ de ocorrência e 0.63 de peso relativo. Observou-se, então, que /o/ pretônico tem mais probabilidade de altear para [u] quando: a) diante de uma vogal alta imediata /i, u/, com de peso relativo 0.92 ; b) precedido de consoantes bilabial, 0.64 ; c) em palavras com sufixo sem vogal alta, peso relativo de 0.51 ; d) em vocábulos pertencentes a classe dos nomes 0.56 ; e e) precedendo imediatamente sílabas tônicas (distância 1), peso relativo de 0.61. Em relação aos traços sociais dos falantes, o fenômeno de alteamento apresentou maior recursividade na fala dos homens, com 0.58 de peso relativo; falantes com Ensino Fundamental, 0.68, e com mais de 46 anos de idade, 0.63 de peso relativo. Concluiu-se, então, que a variação
\end{abstract}

\footnotetext{
${ }_{1}$ Professora da Universidade Federal do Pará/Campus Universitário do Tocantins-Cametá/Pará, Faculdade de Linguagem, Doutora em Linguística (UFC), Mestra em Linguística (UFPA), Especialista em Estudos Culturais da Amazônia (UFPA) e Graduada em Letras - Língua Portuguesa. E-mail: raqmaria@ufpa.br. http://orcid.org/0000-0001-6351-6192.

${ }^{2}$ Graduada do curso de Letras - Língua Portuguesa, Campus Universitário do Tocantins-Cametá/Pará, Faculdade de Linguagem. Email: natanegaia@gmail.com.https://orcid.org/0000-0002-3408-5263
} 
linguística $/ \mathrm{o} / \sim[\mathrm{u}]$, embora seja frequente e estratificada, não é a variante de maior ocorrência na fala dos moradores da zona rural de Baião.

Palavras-chave: Vogal média pretônica. Variação linguística. Alteamento vocálico.

\section{ABSTRACT}

The present work deals with the phenomenon of vowel heightening of the upper middle posterior lo/ in pretonic position in Portuguese spoken in the rural area of the municipality of Baião-PA, Brazil. It aims to analyze the role of linguistic and social factors (gender, age and formal education) in motivating the variable behavior of $/ o / \sim[u]$. The corpus involves a sample of 12 participants, stratified by: age group (15 to 25 years of age, 25 to 45 years, and over 46); gender (male and female); and schooling (elementary and higher education). From the 12 speakers, we obtained a total of 400 speech data, which were treated in Goldvarb X, and analyzed according to the theoretical and methodological assumptions of Variationist Sociolinguistics (Weinreich; Labov; Herzog, 2006). The results showed the heightening of /o/ as the variant of least occurrence, with low frequency of use, $33 \%$ and relative weight 0.32 , and maintenance of $/ o /$ como [o] as a variant of greater occurrence, $67 \%$ of percentage and 0.63 of relative weight. We also observed that pretonic /o/ is more likely to rise to [u] when: a) before an immediate high vowel $/ i, u /$, with a relative weight of 0.92; b) preceded by bilabial consonants, 0.64 ; c) in words with a suffix without a high vowel, relative weight of 0.51 ; d) in nouns 0.56 ; and e) immediately preceded by stressed syllables (distance 1), relative weight of 0.61 . In relation to the social traits of the speakers, the phenomenon of heightening showed greater recursion in the speech of men, with 0.58 of relative weight; speakers elementary- school level of education, 0.68, and over 46 years of age, 0.63 relative weight. We concluded that the linguistic variation $/ o / \sim[u]$, although it is frequent and stratified, is not the most frequent variant in the speech of the residents of the rural area of Baião.

Keywords: Pretonic middle vowel. Linguistic variation. Vowel heightening.

\section{INTRODUÇÃO}

Este estudo aborda o alteamento vocálico da vogal média alta posterior $/ \mathrm{o} / \sim[\mathrm{u}]$ em posição pretônica no português falado na zona rural de Baião-Pará. A abordagem para coleta e análise dos dados foi subsidiada pela Sociolinguística Variacionista (WEINREICH; LABOV; HERZOG, 2006); em estudos acerca das vogais como de Camara Jr., (1970), Silva Neto (1977) e estudos sobre as vogais médias pretônicas em Cametá (RODRIGUES, 2005; COSTA, 2010), Mocajuba (CAMPOS, 2008) e Breves (CASSIQUE et al, 2009), pela perspectiva variacionista.

A variância do sistema vocálico falado no Português Brasileiro é observada desde Camara Jr. (1970), quando considerada a posição ocupada por estes fonemas vocálicos em sílabas tônicas, pretônicas e postônicas. Para este estudo, focalizaremos o processo fonético em que a vogal média posterior pretônica subjacente /o/ eleva o seu traço de altura de vogal média alta para a vogal derivada alta $[\mathrm{u}]$, como em: $\mathrm{t} / \mathrm{o} /$ mate $\rightarrow \mathrm{t}[\mathrm{u}]$ mate.

O trabalho objetiva analisar, por meio de fatores linguísticos e sociais, o processo de alteamento da vogal média posterior alta $/ \mathrm{o} / \sim[\mathrm{u}]$ em posição pretônica no português falado na zona rural do município de Baião-PA. Como objetivos específicos pretendemos: a) observar o alteamento da vogal média posterior no português falado na zona rural do município de Baião-PA; b) identificar 
a correlação entre o fenômeno de alteamento na pretônica /o/ [u] em Baião-PA e os traços sociais dos falantes, como faixa etária, nível de escolaridade e sexo; c) verificar a influência probabilística do contexto silábico de onset vazio e dos contextos com presença dos fonemas vocálicos tônicos orais /i/,/u/, para o alteamento da média pretônica/o/ em [u]; d) examinar os contextos consonantais precedentes e seguintes motivadores ao alteamento de $/ \mathrm{o} / \sim[\mathrm{u}]$.

Temos como hipótese basilar deste estudo que o alteamento de $/ \mathrm{o} / \sim[\mathrm{u}]$ em posição pretônica é o fenômeno de maior ocorrência na região investigada, e esta variação é motivada por fatores internos e externos à estrutura da língua. Por isso, acreditamos que os falantes do sexo masculino, terceira faixa etária (46 anos em diante) e pouca escolaridade (Ensino Fundamental) são os que mais elevam a vogal média posterior em posição pretônica. Quanto aos condicionantes linguísticos: a) no contexto silábico de onset vazio, por constituírem sílabas leves, os fonemas vocálicos orais da tônica /i/, /u/ e sufixos com vogal alta favorecem o alteamento da média pretônica /o/ em [u]; da mesma forma as consoantes do onset da sílaba precedente e seguinte, quando são labiais, propiciam a elevação do traço de altura de /o/.

Para se atingir tais objetivos, efetuamos uma análise de cunho variacionista, pelo viés teórico-metodológico da Sociolinguística Variacionista (WEINREICH; LABOV; HERZOG, 2006). O corpus de análise constitui-se de amostras de falas espontâneas sobre relatos e experiências pessoais, nos moldes tradicionais de coleta de dados laboviana. Diante dos dados obtidos, procuramos realizar uma comparação com pesquisas já existentes na região do baixo Tocantins, como as de Rodrigues (2005), Araújo e Rodrigues (2007), Campos (2008), Moraes (2015) e Araújo (2015), que também estudaram as vogais médias pretônicas no português falado na região da Amazônia Tocantina.

Para melhor compreensão deste trabalho, este se encontra estruturado em três itens: no item 1 apresentamos a fundamentação teórica, Sociolinguística Variacionista e os estudos sobre as vogais médias pretônicas no baixo Tocantins. Em seguida, no item 2 delineiam-se os aspectos teórico-metodológicos adotados nesta pesquisa, como a formação do corpus, locus da pesquisa, coleta e tratamento dos dados. Após isto, no item 3 discorre-se sobre a análise e discussão dos resultados sobre o fenômeno investigado; por fim, expomos as considerações finais e as referências.

\section{AS VOGAIS MÉDIAS PRETÔNICAS NO PORTUGUÊS FALADO NO BRASIL}

Os estudos sobre alteamento das vogais médias pretônicas do português falado no Brasil são bastante produtivos, e foco de muitas pesquisas, principalmente, no Pará, devido à presença de um comportamento altamente variável que tais fonemas vocálicos apresentam na língua falada, seja em posição tônica, pretônica e/ou postônica (final e não final).

A primeira descrição sincrônica completa das vogais do português falado no Brasil é atribuída a Camara Júnior ([1970] 1991), que tomou por base para sua descrição o dialeto falado no Rio de Janeiro.

Norteado pela descrição deste dialeto, Camara Jr. ([1970] 1991) apresenta um triângulo de sete vogais (/a/,/ $/ \varepsilon /, / \mathrm{o} /, / \mathrm{e} /, / \mathrm{o} /, \mathrm{i} /, / \mathrm{u} /)$ para o português brasileiro em posição tônica, com funções distintivas, as quais são reduzidas em posições átonas, devido ao processo fonológico de neutralização ${ }^{3}$ sobre elas incidido, configurando diferentes quadros vocálicos para as vogais no português

\footnotetext{
${ }^{3}$ Wetzels $(1991,1992,1995)$ reinterpreta a proposta de Camara Jr. (1970), levando em consideração os princípios da teoria autossegmental e explica o processo de neutralização das vogais médias em termos da geometria dos traços (CLEMENTS, 1989), "com altura vinculada a traços de abertura, aberto1, aberto2 e aberto3, o traço neutralizado é desligado e substituído pelo valor oposto" (COSTA, 2010).
} 
brasileiro, a depender das posições ocupadas nos vocábulos: a) 5 vogais pretônicas (/a/, /e/, /o/, /i/, /u/); b) quatro postônicas não finais (/a/, /e/, /i/, /u/); e 3 em posição postônica final (/a/, /i/, /u/).

No estado do Pará são encontrados diversos estudos de cunho fonético-fonológico que verificam o alteamento vocálico, como o de Rodrigues (2005) que investigou na zona urbana e rural de Cametá o alteamento das pretônicas /e/ e /o/ e da tônica do /o/, a partir de 4.328 dados de fala. Como resultado, o autor obteve percentual de alteamento de /e/ e /o/ de $70 \%$ na posição pretônica de $35 \%$ na tônica .

Araújo e Rodrigues (2007), analisando a variação da média pretônica /o/, verificam um percentual de $40 \%$ e peso relativo de .41 , e para a ausência de elevação um percentual de $60 \%$ e peso relativo de .60. Em Campos (2008), estudo realizado sobre o português falado na zona urbana do município de Mocajuba-PA, obteve-se um resultado mais favorável ao processo de aplicação da regra de alteamento de /e/ $\sim[\mathrm{i}] \mathrm{e} / \mathrm{o} / \sim[\mathrm{u}]$ em posição pretônica no município de MocajubaPará, pois o peso relativo aponta .50 para a presença e .50 para a ausência, dos 2.227 dados efetivamente obtidos para análise.

Moraes (2015) caracterizou acusticamente as vogais médias pretônicas /e/ e /o/ faladas em Cametá-Pará, e impetrou um total de 455 ocorrências de vogais médias anteriores e 473 vogais posteriores na fala de 18 informantes naturais da cidade de análise, levando em consideração o sexo, a faixa etária e a escolaridade. A partir das variantes elencadas, o alteamento teve a maior probabilidade de ocorrência, com 77 dados para [i] < /e/ e 72 para a vogal alta $[u]</ o /$, enquanto a derivada baixa $[\varepsilon]$ teve 112 ocorrências e para o [0] 136 ocorrências.

Apontamos ainda, o estudo de Silva Neto (1977), um dos pioneiros a lançar-se sobre o fenômeno de alteamento das vogais na região paraense. Para o autor, o estado do Pará, grosso modo, divide-se em três regiões distintas: a primeira região é chamada de "estrada de ferro"; a segunda é a região "do Salgado"; a terceira é a região "dos rios". Esta última região é a área "onde se troca $o$ tônico por $u$ (por exemplo, no Tocantins).

Partindo da observância destes estudos acerca do comportamento variável das vogais pretônicas no português falado do Brasil, esta pesquisa revela a convergência do seu objeto de análise ao pressuposto de Labov (2008, p. 247) que aponta a existência de "grande variedade na fala dentro de um grupo social". Portanto, analisar as vogais pelo ponto de vista da relação entre o linguístico e o social, denota darmos nossa contribuição significativa no que se refere ao funcionamento da língua no seio de uma comunidade de fala e em contexto social de uso; significa ainda dizermos que há entrelaçamento entre a variação/mudança fonológica e as características sociais dos falantes no ato comunicativo.

\section{PROCESSO METODOLÓGICO: DA COMUNIDADE PESQUISADA}

Este trabalho segue a orientação dos pressupostos teórico-metodológicos da Sociolinguística quantitativa ou modelo laboviano de análise, e tende a justificar a influência dos fatores linguísticos e sociais na variação do fenômeno de alteamento vocálico da pretônica /o/. A amostra compreende um total de 12 participantes, ${ }^{4}$ estratificados em: a) nível de escolaridade (6 com Ensino Fundamental incompleto) e 6 com Ensino Superior); b) faixa etária (4 entre 15 e 25 anos, 4 entre 26 e 45 anos

\footnotetext{
${ }^{4}$ Os critérios elencados para a seleção dos informantes foram os seguintes: ser baionenses, nascidos e residentes no município, zona rural ou que tenham chegado a este município até os sete anos de idade, na área rural, e que não tenham se deslocado da região, onde moram por mais de dois anos consecutivos; e possuir dentição completa, a fim de que as articulações dos fonemas fossem o mais natural possível.
} 
e 4 com idade igual ou superior a 46 anos); c) sexo (6 participantes do sexo masculino e 6 participantes do sexo feminino); todos pertencentes à zona rural do município da pesquisa.

A coleta dos dados ${ }^{5}$ foi realizada por meio de entrevistas livres envolvendo relatos de experiências pessoais dos informantes, lendas, casos, trabalho, emprego, política etc. Ato contínuo, realizamos a transcrição dos grupos de força previamente selecionados em que os itens lexicais com a variável dependente (presença de alteamento e ausência de alteamento) se manifestaram. Tarefa pela qual foram identificados um total de $400^{6}$ dados oriundos de 360 minutos de gravação, em média 30 dados de cada 30 minutos de gravação por participante. Os dados foram analisados estatisticamente pelo pacote dos programas da série Goldvarb X.

Deste modo, consideramos neste estudo para análise do "alteamento da vogal média pretônica posterior /o/ [u] em posição pretônica", a partir da presença e ausência de alteamento, treze (13) fatores condicionadores do objeto de nossa investigação: a) Variáveis sociais: sexo (masculino e feminino); faixa etária (15 a 25 anos, 26 a 45 anos e 46 em diante); escolaridade (Ensino Fundamental e Ensino Superior); b) Variáveis linguísticas: fonema vocálico da tônica quando a pretônica é oral; fonema vocálico da tônica quando a pretônica é nasal; vogal contígua; distância da sílaba tônica; consoante do onset; consoante do onset da sílaba seguinte; peso silábico; sufixos; classe gramatical e número de sílabas.

\section{O ALTEAMENTO VOCÁLICO DA MÉDIA PRETÔNICA /O/ NO PORTUGUÊS FALADO NA ZONA RURAL DE BAIÃO-PA}

O corpus colhido de 12 participantes totalizou em 400 manifestações da variável dependente, com 131 ocorrências de presença de alteamento, percentual de 33\%, e peso relativo de 0.327 e 269 dados de ausência, percentual de $67 \%$ e peso relativo de 0.673 . Portanto, a presença de alteamento é de menor significância no português falado na zona rural do município de Baião-Pará.

Tabela 1 - Significância da variação das médias pretônicas no falar rural de Baião (PA).

\begin{tabular}{c|c|c|c}
\hline Variantes da Variável dependente & Valor/Aplicação & Percentual & Peso relativo \\
\hline Presença de alteamento & $131 / 400$ & $33 \%$ & 0.327 \\
\hline Ausência de alteamento & $269 / 400$ & $67 \%$ & 0.673 \\
\hline Total & 400 & $100 \%$ & 1.00 \\
\hline
\end{tabular}

Fonte: Elaboração própria

Os resultados apresentados neste estudo, se comparados ao percentual de presença de alteamento obtido para Breves (CASSIQUE 7 , 2003) e Cametá (RODRIGUES $\left.{ }^{8}, 2005\right)$, apresentam paridades no uso deste fenômeno, considerado como pronúncia marcada do dialeto interiorano da Amazônia paraense (CASSIQUE, 2003). Assim, os resultados expressos na Tabela 1 acima corroboram os obtidos por outras pesquisas voltadas para a presença de alteamento, conforme Tabela 2, que segue.

\footnotetext{
${ }^{5}$ O corpus da pesquisa foi constituído entre os anos de 2017 e 2019, em diferentes pontos da área rural do município de Baião.

${ }^{6}$ Só consideramos para análise os dados de excelente sinal sonoro, capazes de nos fornecer uma segura compreensão oitiva.

${ }^{7}$ Estudo sobre a área urbana do município de Breves.

${ }^{8}$ Estudo sobre a área urbana e rural do município de Cametá.
} 
Tabela 2 - O processo de alteamento da médias pretônicas nas cidades interioranas do Pará

\begin{tabular}{|c|c|c|}
\hline Presença de alteamento & Aplicação & Percentuais \\
\hline 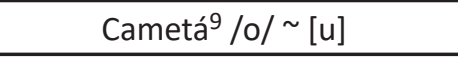 & $682 / 1690$ & $40 \%$ \\
\hline Breves /o/ [u] e /e/ [i] $]^{10}$ & $1.128 / 2.624$ & $43 \%$ \\
\hline Cametá /o/ [u] $]^{11}$ & $71 / 455$ & $16 \%$ \\
\hline Belém /o/ [u] $]^{12}$ & $31 / 719$ & $4,3 \%$ \\
\hline Mocajuba /o/ [u] e /e/ [i] ${ }^{13}$ & $1093 / 2227$ & $49 \%$ \\
\hline Mocajuba /o/ [u] ${ }^{14}$ & $140 / 1389$ & $10 \%$ \\
\hline Baião /o/ [u] $]^{15}$ & $131 / 400$ & $33 \%$ \\
\hline
\end{tabular}

Observamos que o processo de alteamento no Pará não é a variante predileta entre os falantes, visto que não se manifesta como fenômeno de maior ocorrência, em nenhuma das cidades expostas na Tabela 2, embora já tenha sido atestado como um dos traços fonéticos bem marcados da linguagem do Norte do Brasil, como observou Nascentes (1964), neste período sincrônico parece que tais regiões estão perdendo esta marca linguística identitária.

\subsection{Fatores linguísticos e extralinguísticos estatisticamente relevantes}

Dos treze grupos de fatores considerados como categorias de análise neste trabalho, oito foram significativos para explicar o fenômeno do alteamento $/ \mathrm{o} / \sim[\mathrm{u}]$ na zona rural de Baião, sendo 5 linguísticos (vogal contígua, consoante do onset, sufixos, classe gramatical, distância da sílaba tônica) e 3 fatores sociais (sexo, idade e escolaridade), os quais serão apresentados na análise em tela, em ordem de significância.

Em relação à vogal contígua, conforme dados no Gráfico 1, observamos que a presença da vogal contígua alta imediata /i/ e / $\mathrm{u}$ / é forte condicionadora da presença de alteamento na fala dos baioneneses, com peso relativo de 0.92 ; autorizando pronúncias frequentes como "c $[\mathrm{u}] \mathrm{m} / \mathrm{i} / \mathrm{go}$ e c[u]ns/u/mo"; seguido da vogal contígua não imediata, como no exemplo "m[u]caj/u/ba", com peso relativo elevado de 0.87 . Enquanto as vogais não altas não se demonstraram significativas a este fenômeno vocálico, peso relativo de 0.323 , não favorecendo, portanto, o alteamento.

\footnotetext{
${ }^{9}$ Zona urbana e rural (RODRIGUES, ARAÚJO, 2007).

10 Análise sociolinguística Zona urbana (CASSIQUE, CRUZ, DIAS, 2007).

${ }^{11}$ Análise acústica, zona rural (MORAES, 2015).

12 Belém (CRUZ, 2013).

${ }^{13}$ Análise sociolinguística, zona urbana (CAMPOS, 2008).

${ }^{14}$ Análise acústica, zona rural (ARAÚJO, 2015).

15 Zona Rural.
} 
Gráfico 1 - Significância da vogal contígua para o alteamento da vogal média posterior /o/.

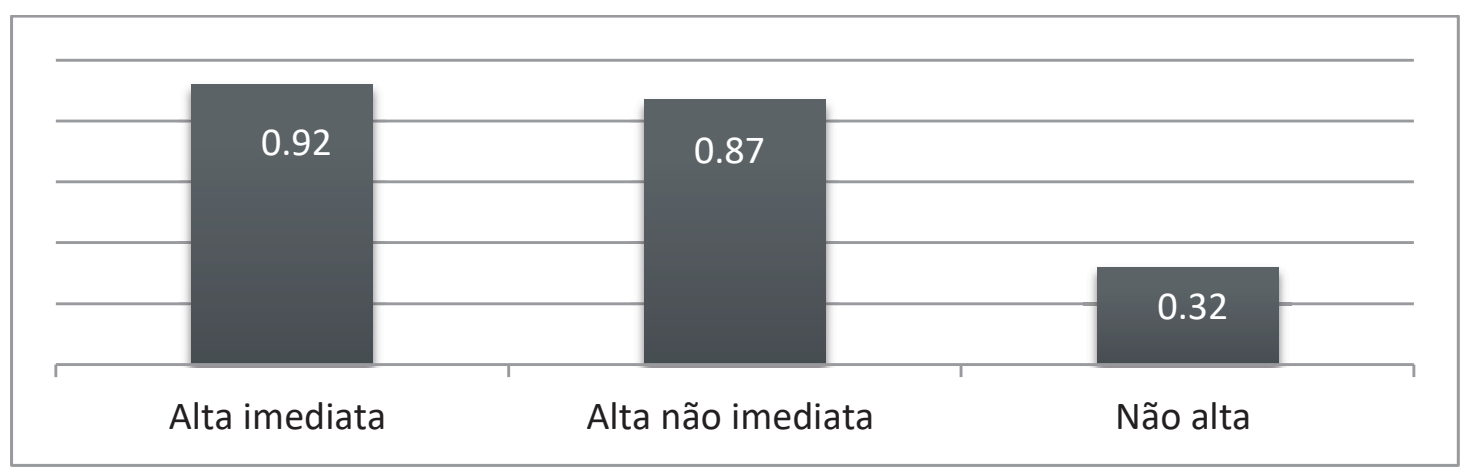

Fonte: Elaboração própria

Este resultado evidencia a tendência para a harmonização vocálica, pela motivação que /i/ e /u/tônicos imediatos, $[\mathrm{c} / \mathrm{u} / \mathrm{m} / \mathbf{i} / \mathrm{gu}][\mathrm{c} / \mathrm{u} / \mathrm{ns} / \mathbf{u} / \mathrm{mu}]$ e não imediatos $[\mathrm{m} / \mathrm{u} / \mathrm{caj} / \mathbf{u} / \mathrm{ba}]$ exerceram sobre a pretônica /o/, nivelando a altura entre a vogal aspirante ao fenômeno de alteamento e a vogal alta adjacente.

Quanto às consoantes do onset da sílaba seguinte, as mais significativas para ocorrência do alteamento foram: a) as bilabiais encontradas em 'cobertor', por exemplo, com peso relativo de 0.64; os onsets ramificados, como 'completar', peso relativo de 0.53; as consoantes dorsais, como em 'conquista', peso relativo 0.51. Já as consoantes coronais, por exemplo "poder", peso relativo baixo de 0.42 , não se mostraram favorecedoras do processo de alteamento, conforme observado no Gráfico 2.

Gráfico 2 - Significância dos fatores relacionados à natureza do onset da sílaba seguinte.

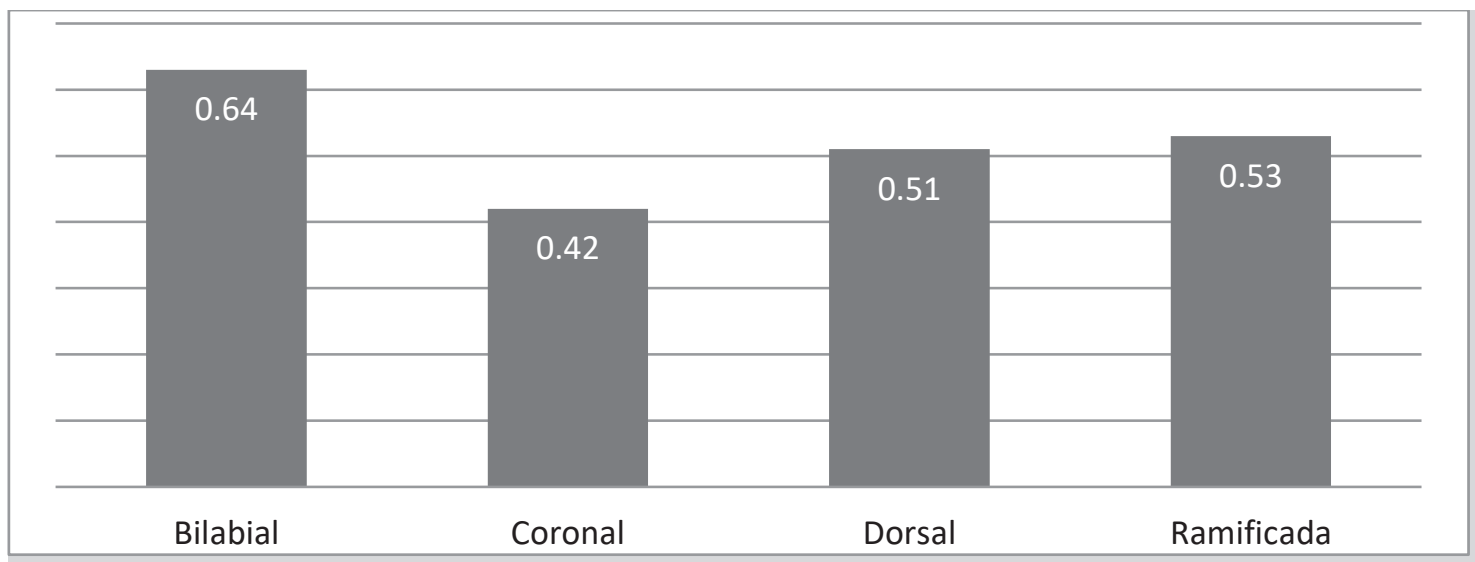

Fonte: Elaboração própria.

A influência das labiais e dorsais alteamento de /o/ atribuímos à partilha de traços articulatórios semelhantes: nas consoantes 'labiais' o traço compartilhado com [u] é o labial e nas dorsais acreditamos que tanto a altura como a constrição da região central ou posterior da língua é mais acentuada entre $[\mathrm{u}]$ e $[\mathrm{k}, \mathrm{g}]$. Portanto, o alteamento é oriundo da tentativa de aproximação de tais articulações, tendo em vista torná-las mais cômodas para o falante.

Tal verificação confirma a hipótese testada para esta variável ao considerar o ponto de articulação / posição da língua na produção do fonema seguinte, no qual ficou constatado que o traço 
labial, usado tanto nos fonemas consonantais como em [u], favorece o emprego de [u]; já nas dorsais são os traços + alto e + posterior compartilhados com $[\mathrm{u}]$ que favorecem o alteamento, $[\mathrm{pru} / \mathrm{ku} / \mathrm{rar}]$.

Há de se destacar ainda que, embora a referida propensão para o alteamento esteja para o onset bilabial, percentual de $42 \%$, infere-se que a influência do onset ramificado para a elevação da média /o/, percentual de 50\%, seja justificado pelo peso articulatório recaído sobre o grupo consonantal ${ }^{16}$ que sucede a pretônica, resultando numa pronúncia "pesada". Isto, portanto, diminui a força articulatória da pretônica /o/, tornando-a mais fraca, débil, e a elevando automaticamente para [u], para novamente esta força articulatória se elevar na sílaba com o grupo consonantal e na tônica.

Sobre o condicionamento dos sufixos, o alteamento foi analisado pelas variáveis: sem sufixo, sufixo sem vogal alta e sufixo com vogal alta, $O$ peso relativo demonstra valores muitos próximos entre os sufixos sem vogal alta, peso relativo de 0.51 , e os vocábulos sem sufixo, 050 de peso relativo, manifestando relevância mediana para o alteamento das vogais médias, atestado pelo Gráfico 3 .

Gráfico 3 - Ocorrência de sufixos no processo de alteamento

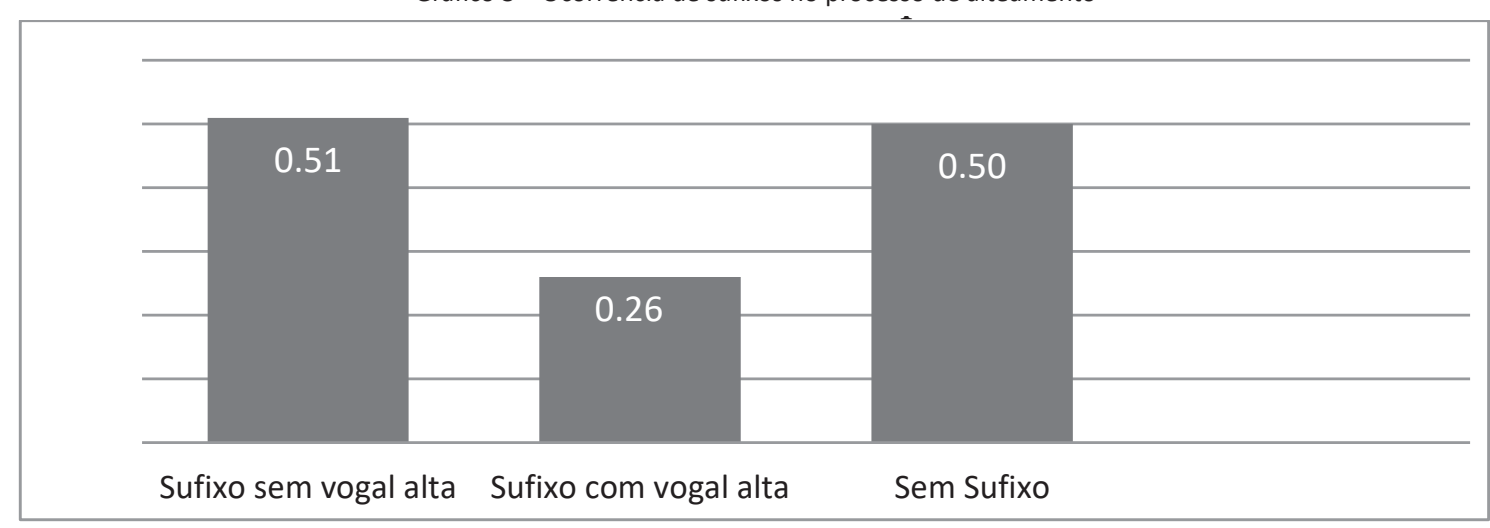

Fonte: Elaboração própria

Ao contrário do que poderíamos supor, pela hipótese para este grupo de análise, a altura das vogais dos sufixos não se expôs saliente ao processo de alteamento das vogais médias, pois mostrou baixa relevância probabilística, com peso relativo de 0.26 .

Da mesma forma a classe gramatical do vocábulo não expôs resultados tão içados para a realização de alteamento, exercendo a classe dos nomes maior pressão ao alteamento com peso relativo 0.56; enquanto o verbo consubstanciou-se abaixo do nível da significância, peso relativo de 0.41. A hipótese para este fator estaria na maior incidência de alteamento nos verbos, visto que esta classe gramatical é mais provável de sobrevir nas falas espontâneas, entretanto, os nomes apresentaram-se mais significativos. O não favorecimento de alteamento de [o] pelos verbos poderia ser atribuído à frequência elevada de dados no corpus, percentual de $44 \%$, de nomes, contra $19 \%$ de percentual para os verbos.

${ }^{16}$ Para este grupo, as dorsais apresentaram percentual de $27 \%$ e as coronais de $25 \%$. 
Gráfico 4 - O favorecimento da classe gramatical para a presença de alteamento

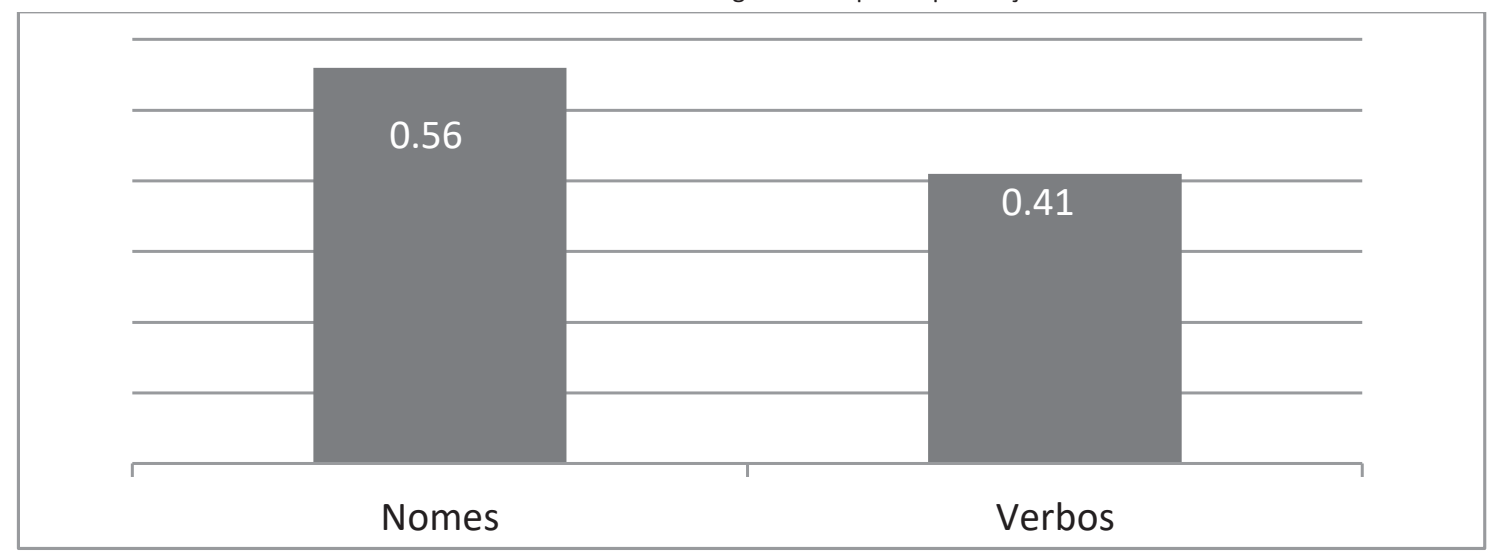

Fonte: Elaboração própria

Sobre a distância da vogal tônica, medida pela distância $1(\mathrm{p}[\mathrm{u}]$ lícia), distância 2 (c[u]nversar), distância 3 (c[u]nfinamento) e distância 4 (s[u]lidariedade), A distância 1 da sílaba tônica, segundo o previsto pela hipótese, favoreceu expressivamente o processo de alteamento da vogal pretônica posterior /o/, com peso relativo de 0.61 , destacando que, quanto mais próxima a sílaba tônica estiver da pretônica, mais possibilidade de altear esta apresentará.

Gráfico 5 - Distância da sílaba tônica da pretônica /o/ alvo do processo de alteamento.

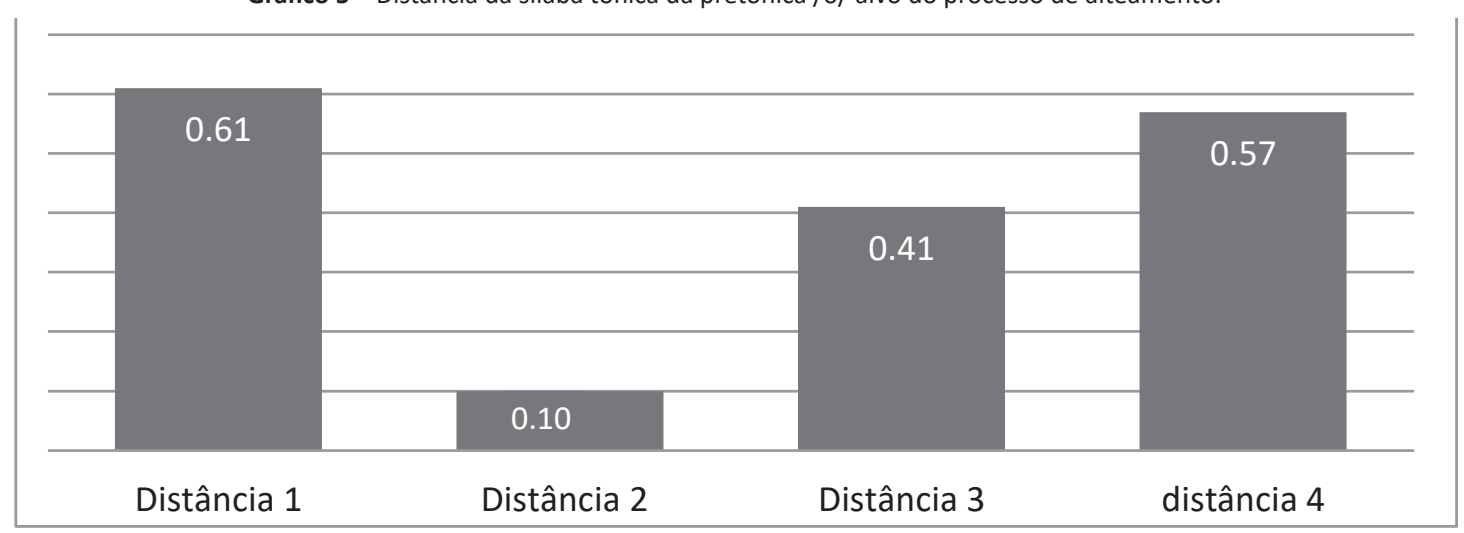

Fonte: Elaboração própria

A hipótese deste grupo previa a distância 1 da sílaba pretônica em relação à tônica como a favorecedora do alteamento e os dados confirmaram isto, pois, quanto menor a distância entre tônica e pretônica, maior a aplicação da regra de alteamento. Por outro lado, se retirarmos a distância 1, percentual de 38\%, observamos uma linha ascendente na ocorrência de alteamento em relação às distâncias 2,3 e 4 , percentuais de $6.5 \%, 26 \%$ e $57 \%$, respectivamente, isto é, quanto mais distante a vogal média está da vogal tônica, maior a possibilidade dela altear, pois isto é o apontado pela distância 4 . 


\subsection{Fatores sociais}

Dentre os fatores extralinguísticos estudados, o fator escolaridade foi o mais acentuado traço social favorecedor da elevação de /o/ no português falado na zona rural de Baião. No Gráfico 6, a maior escolaridade (Ensino Superior) exibiu ínfima possibilidade de altear as médias pretônicas, com peso relativo de 0.36 , ao passo que a probabilidade de alteamento do /o/ encontra-se mais nas produções linguísticas dos falantes com Ensino Fundamental, apresentado pelo peso relativo de 0.63. A partir deste resultado, confirmamos a hipótese levantada neste estudo de que há maior probabilidade de elevação de /o/ para [u] entre os falantes com Ensino Fundamental incompleto do que os com Ensino Superior.

Deste fator social infere-se a ideia de que os contextos educacionais influenciam a identidade linguística do falante e a regressão do processo de alteamento de /o/, seja na tônica, como apontou Rodrigues (2005), ${ }^{17}$ com peso relativo de 0.28 para o Ensino Médio, maior nível de escolarização controlado pelo autor; seja na pretônica, como constatou Campos (2008), ${ }^{18}$ em que os falantes com mais de 10 anos de escolaridade manifestaram probabilidade de uso de vogal de 0.37 de peso relativo; ou na postônica não final, como o afirmado por Costa (2010), ${ }^{19}$ com apenas 0.32 de peso relativo para o alteamento de /o/ pelos falantes de nível superior.

Gráfico 6 - Efeito do tempo de permanência na escola sobre o alteamento do /o/ em posição pretônica.

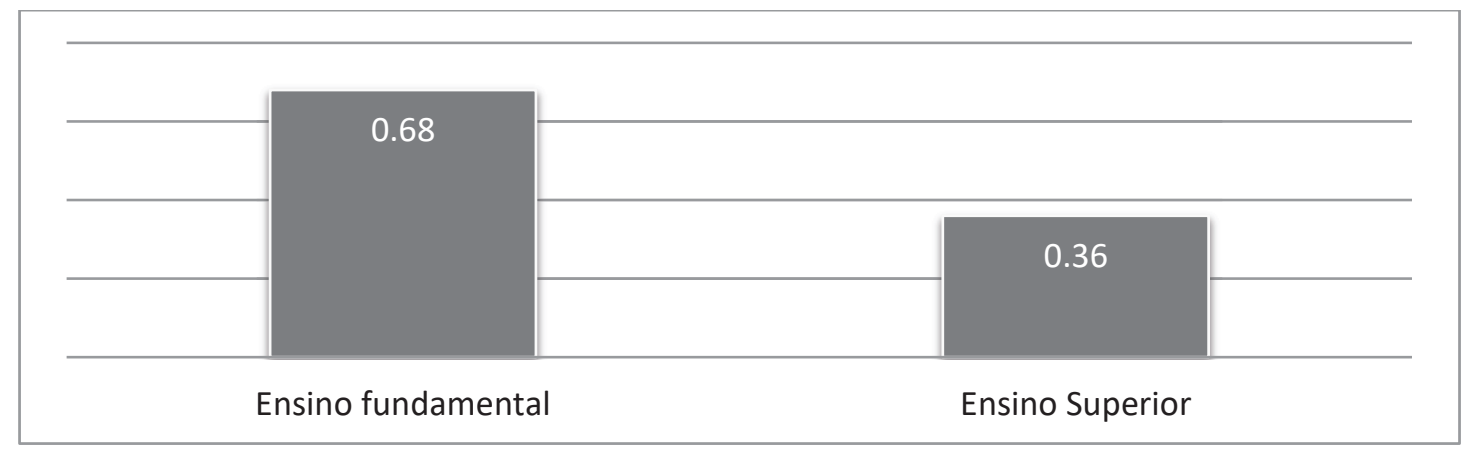

Fonte: Elaboração própria

Assim, quanto menor a escolaridade, maior será o favorecimento de expressões como $\mathrm{d}[\mathrm{o}]$ mingo $<\mathrm{d}[\mathrm{u}]$ mingo, $\mathrm{s}[\mathrm{o}]$ brinho $<\mathrm{s}[\mathrm{u}]$ brinho, $\mathrm{c}[\mathrm{o}]$ migo $<\mathrm{c}[\mathrm{u}]$ migo. Acreditamos assim que o nível de conhecimento do falante sobre a gramática da língua é proporcional ao seu nível de escolaridade. Fato comprovado por Labov (1996) no estudo do inglês de Nova Iorque, quando observou que falantes menos escolarizados eram mais predispostos às formas não padrão da língua, ao passo que falantes com nível de escolaridade mais elevado empregavam de forma mais significativa as formas padrão.

Dias et al. (2007) verificaram que 50\% dos informantes analfabetos realizaram alteamento da vogal pretônica, obtendo um peso relativo de 0.62 , por outro lado, $42 \%$ dos informantes que tinham o Ensino Fundamental realizaram o alteamento, peso relativo de 0.52. Araújo e Rodrigues (2007, p. 37) verificaram que para o /o/ "são somente os falantes com Ensino Fundamental [...]

\footnotetext{
17 /e/ e /o/

18 /e/ e /o/

19 /o/
} 
que favorecem a atuação da regra de elevação, enquanto que os falantes com Ensino Médio inibem a não aplicação da regra de elevação". Logo, o alteamento de /o/ [u] encontra-se ainda preservado na fala dos sujeitos com pouco contato com a língua culta ensinada pelas escolas. É provável que o alteamento de /o/ seja reduzido com o contato e posterior domínio da ortografia da língua portuguesa.

Em relação ao sexo do falante no processo de alteamento de /o/, observamos no Gráfico 7, abaixo, que os homens, com peso relativo 0.58 , apresentam maior índice de alteamento da posterior, enquanto as mulheres, peso relativo de 0.42 tendem probabilisticamente ao uso de /o/.

Gráfico 7 - O fator sexo no processo de alteamento

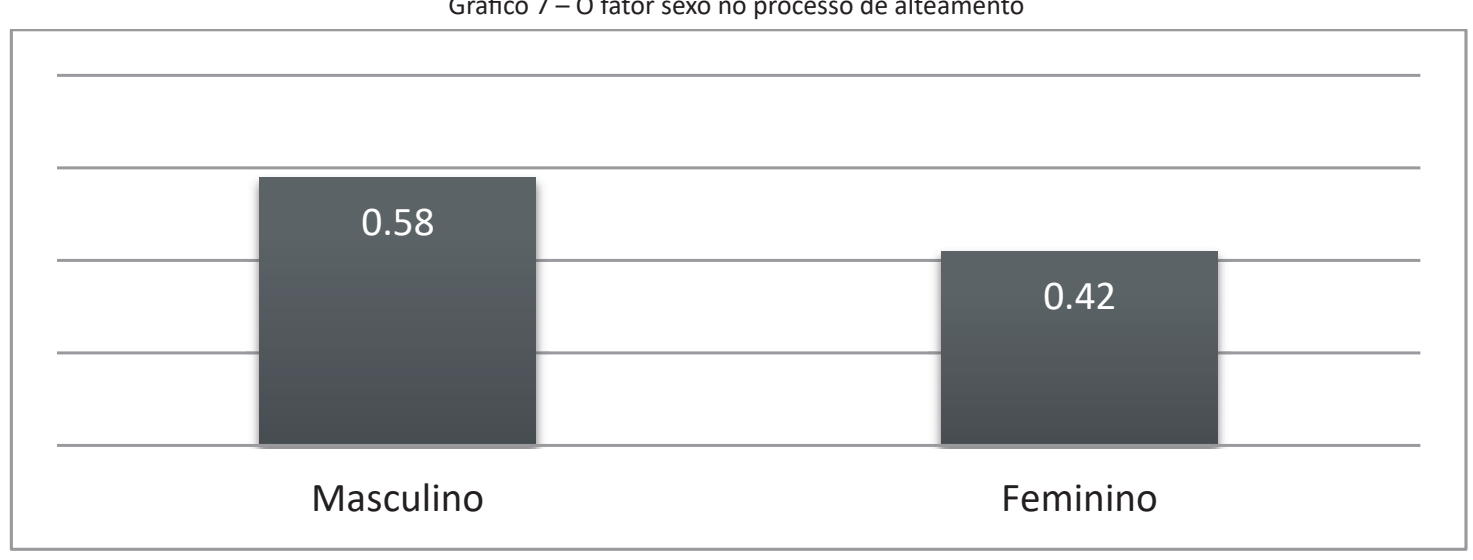

Fonte: Elaboração própria

Conforme a hipótese para este grupo, os dados confirmaram que existe maior probabilidade de haver a presença de alteamento na fala dos sujeitos do sexo masculino, resultado que nos leva a inferir que as mulheres buscam empregar uma linguagem mais prestigiada em sua fala, até mesmo com o intuito de obter maior reconhecimento de seu papel e status social; do contrário, os homens não tendem a essa preocupação, pois naturalmente são menos cobrados e mais respeitados pelos cargos e papéis desempenhados socialmente.

No fator idade, conforme Gráfico 8, abaixo, a partir dos resultados da pesquisa exposta aqui, atestamos o favorecimento do alteamento pelos participantes com mais de 46 anos de idade, com peso relativo de 0.63 . Partindo deste resultado, confirmamos a hipótese levantada neste grupo de análise, que atribuía à terceira faixa etária maior probabilidade de favorecimento da vogal média posterior /o/; e os dados expressos acima comprovaram isto.

O grupo constituído por pessoas de 26 a 45 anos ocupa o segundo lugar nas possibilidades de altear as vogais médias em posições pretônicas, peso relativo de 0.50 , enquanto os mais jovens de 15 a 25 anos mostram-se resistentes à aplicação da regra variável em análise, portanto mais conservadores, inibindo assim o alteamento, com apenas 0.36 de peso relativo.

Na gradação etária visualizada no Gráfico 8, estabelecida pela curva ascendente de elevação da idade, os mais jovens, de 15 a 25 anos, não apresentaram inclinação à introdução do processo de alteamento de /o/ na fala em investigação, e há forte tendência de /o/ substituir, progressivamente, as formas utilizadas pelos grupos de falantes da segunda e terceira faixa etária, isto é, o /o/ alteado para $[u]$, uma fala representativa de estados de língua anteriores. Assim, não estamos diante de uma mudança em progresso na comunidade investigada, pois os jovens despontam como agentes e/ou condutores da mudança linguística (LABOV, 2001). 


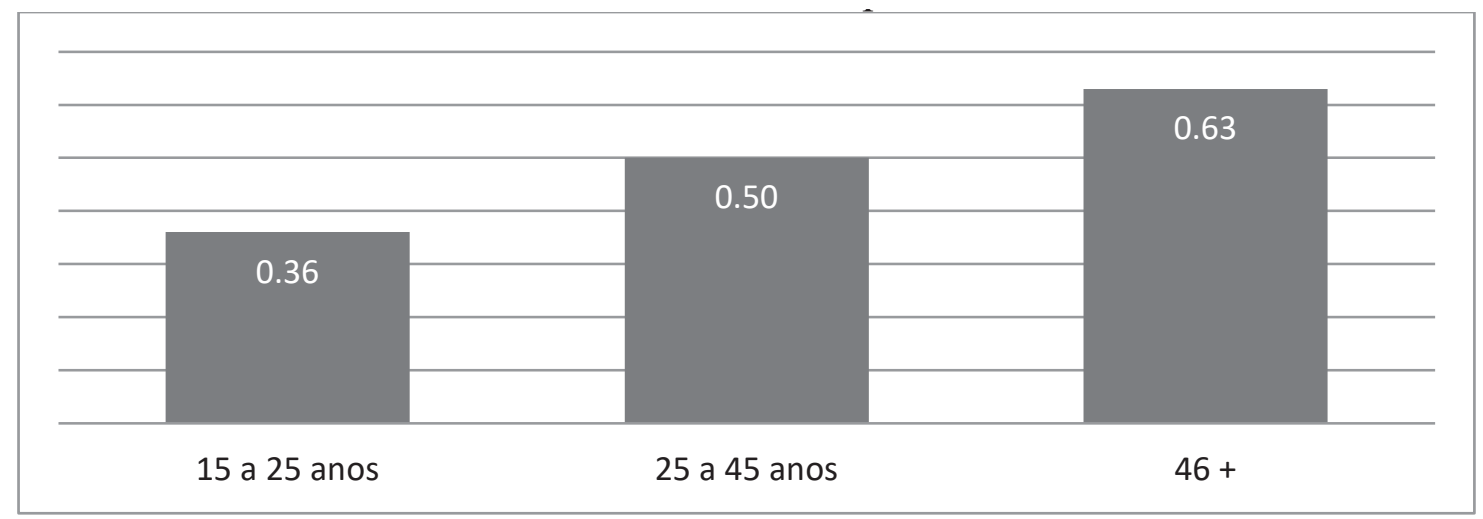

Fonte: Elaboração própria

Os dados expressos no Gráfico 8 manifestam-se em uma escala ascendente, pois o uso significativo de /o/ alteado para $[\mathrm{u}]$ é proporcional ao aumento de idade do falante, logo quanto mais idade possuir o falante, mais ele usará [u] e não /o/. Isto pode ser justificado pelo desprendimento, nesta fase de vida do falante, de um comportamento mais formal e automatizado, e de mais segurança linguística para se expressar de forma natural e vernacular.

Em relação ao grupo de jovens (de 15 a 25 anos) apresentar maior índice de preservação da vogal média em posição pretônica na zona rural de Baião nos é curioso, porque este grupo está diretamente ligado aos contextos interacionais menos formais e mais interligados e conectados digitalmente entre si pelas redes de amizades e relacionamentos sociais, estando ainda, menos preocupados com as regras sociais e imposições formais de uso das línguas. Então a tendência seria a forma alteada, mas não é isso que acontece, os jovens preferem a forma canônica da língua, isto é, a vogal subjacente $/ \mathrm{o} /$.

Este resultado ainda aponta para a variação entre /o/ e [u], que esta última variante tende cada vez a mais desaparecer da linguagem falada pelos moradores da zona de rural de Baião, já que sua predileção está entre os falantes da segunda e terceira faixa etária; e, como tem baixa significância entre os mais jovens, poderá tender à regressão cada vez mais intensa de seu uso entre os baionenses.

Pela coerência deste pressuposto, cruzamos os fatores sociais Faixa Etária e Sexo e Faixa Etária e Escolaridade vislumbrando maior aproximação e lapidação dos resultados desta análise. Desta forma, para o primeiro cruzamento - Faixa Etária e Sexo, observamos que o índice mais profícuo de alteamento surge na terceira faixa etária com percentual de $47 \%$ e na fala dos homens, o que reafirma o exposto nos gráficos 7 e 8 para os fatores sexo e faixa etária, respectivamente; predominando a ausência de alteamento na fala das mulheres, da primeira faixa etária.

Tabela 3 - Cruzamento entre as variáveis sociais faixa etária e sexo em relação ao alteamento /o/ - [u]

\begin{tabular}{c|c|c|c|c|c|c}
\hline \multirow{2}{*}{$\begin{array}{c}\text { Variáveis } \\
\text { sociais }\end{array}$} & \multicolumn{2}{|c|}{$\mathbf{1 5}$ a $\mathbf{2 5}$ anos } & \multicolumn{2}{c|}{$\mathbf{2 6}$ a $\mathbf{4 5}$ anos } & \multicolumn{2}{c}{$\mathbf{4 6}$ em diante } \\
\cline { 2 - 7 } & Aplicação & Percentual & Aplicação & Percentual & Aplicação & Percentual \\
\hline Masculino & $28 / 70$ & $40 \%$ & $21 / 63$ & $33 \%$ & $31 / 66$ & $47 \%$ \\
\hline Feminino & $10 / 74$ & $14 \%$ & $17 / 50$ & $34 \%$ & $24 / 77$ & $31 \%$ \\
\hline Total de dados & $38 / 144$ & & $38 / 113$ & & $55 / / 143$ & \\
\hline
\end{tabular}

Fonte: Elaboração própria 
Destacamos um dado curioso, observado na primeira faixa etária, o percentual elevado, embora não mais significativo da análise, de alteamento na fala dos homens pertencentes a este grupo etário. À exceção deste resultado, as mulheres mais jovens despontam ao uso elevado de manutenção da média pretônica /o/, pelo panorama exposto na Tabela 3, o diferencial nestes resultados é estabelecido por elas. Neste ponto pautamo-nos em Labov (2001, p. 34 - tradução nossa) ao argumentar em defesa da necessidade de olharmos mais detalhadamente para o indivíduo falante, o qual só poderá ser "entendido como o produto de uma história social única e na intersecção dos padrões linguísticos de todos os grupos sociais e categorias que definem esse indivíduo". ${ }^{20}$

A mulher conquista cada vez mais espaço de destaque e liderança social na comunidade onde atua, e este traço forte, ao que indica, ganha também robusteza pela variedade linguística que usa, e por isto adota aquela de maior prestígio social.

Pelo cruzamento de Faixa Etária e Escolaridade, torna-se mais evidente o alteamento como fenômeno recorrente na fala dos sujeitos de pouca escolaridade quer pertencentes à segunda e a terceira faixa etária, com $46 \%$ e $65 \%$ de percentual, respectivamente. Enquanto falantes de nível superior manifestam baixa aplicabilidade de uso da regra variável em análise nas três faixas etárias analisadas, como o apontado na Tabela 4, que segue.

Tabela 4 - Cruzamento entre as variáveis sociais faixa etária e escolaridade em relação ao alteamento /o/ - [u]

\begin{tabular}{c|c|c|c|c|c|c}
\hline \multirow{2}{*}{$\begin{array}{c}\text { Variáveis } \\
\text { sociais }\end{array}$} & \multicolumn{2}{|c|}{$\mathbf{1 5}$ a $\mathbf{2 5}$ anos } & \multicolumn{2}{c|}{$\mathbf{2 6}$ a $\mathbf{4 5}$ anos } & \multicolumn{2}{c}{$\mathbf{4 6}$ em diante } \\
\cline { 2 - 7 } & Aplicação & Percentual & Aplicação & Percentual & Aplicação & Percentual \\
\hline $\begin{array}{c}\text { Ensino } \\
\begin{array}{c}\text { Fundamental } \\
\text { incompleto }\end{array}\end{array}$ & $21 / 65$ & $32 \%$ & $27 / 59$ & $46 \%$ & $28 / 43$ & $65 \%$ \\
\hline $\begin{array}{c}\text { Ensino } \\
\text { Superior }\end{array}$ & $17 / 79$ & $22 \%$ & $11 / 54$ & $20 \%$ & $27 / 100$ & $27 \%$ \\
\hline Total de dados & $38 / 144$ & & $38 / 113$ & & $55 / 143$ & \\
\hline
\end{tabular}

Fonte: Elaboração própria

Examinar a faixa etária neste grupo de fatores, pelas distintas idades dos falantes nos mostra uma variação, como propôs Labov (1963), estável neste dado curso da história. Portanto, o que podemos argumentar, a partir de nossos dados, é que o não uso pela faixa etária mais jovem, da forma alteada $/ \mathrm{o} / \sim[\mathrm{u}]$, e por falantes apenas com o ensino fundamental, pode nos dar indícios de que este fonema vocálico em variação no português falado em Baião-PA caminha para um estágio de desaparecimento, haja vista termos somente $32 \%$ de uso, nesta faixa etária, e quanto mais a idade avança, mais há o crescimento da predileção de [u]. E quando tais falantes alcançarem níveis de escolarizações mais elevados a tendência será mitigar este uso, consequentemente caindo no desuso tal forma oral.

\footnotetext{
${ }^{20}$ No original: understood as the product of a unique social history, and the intersection of the linguistic patterns of all the social groups and categories that define that individual.
} 


\section{CONSIDERAÇÕES FINAIS}

O estudo do processo de modificação da vogal pretônica média alta posterior no português falado no município de Baião-PA, zona rural, possibilitou-nos verificar o comportamento linguístico da manutenção versus ausência de alteamento da pretônica e, principalmente, da presença/ausência de alteamento da vogal supracitada, para observarmos se o fenômeno linguístico em questão sofre ou não interferências de fatores linguísticos e/ou extralinguísticos.

Como resultado constatamos que a vogal pretônica média alta posterior $/ \mathrm{o} / \sim[\mathrm{u}]$ apresenta maior probabilidade para ausência do alteamento com peso relativo de 0.673 do que para a presença, peso relativo de 0.327 . A análise quantitativa manifestou ainda a significância de fatores linguísticos e sociais para a presença deste fenômeno, demonstrando que a presença das vogais contíguas altas imediatas /i/ e /u/, com peso relativo de 0.92; as consoantes bilabiais do onset da sílaba seguinte, com peso relativo de 0.64 ; a classe gramatical dos nomes com peso relativo 0.56 , influenciam o alteamento da vogal postônica /o/.

Quanto aos fatores extralinguísticos influenciadores da ocorrência de alteamento do /o/ foram selecionados a baixa escolaridade, com peso relativo de 0.63 , para os falantes com ensino fundamental; o sexo masculino, peso relativo de 0.58 ; e a faixa etária de 46 anos em diante com a significância de peso relativo de 0.63 .

Podemos dizer que a facilidade com que os participantes têm acesso aos bens tecnológicos e midiáticos como televisão, rádio, internet, celular, entre outros, vem contribuindo para adoção de uma linguagem mais formal, o que nos leva a ressaltar que os moradores do município da zona rural de Baião, tendem a perder as marcas variacionistas de alteamento da pretônica.

\section{REFERÊNCIAS}

ARAÚJO, Marivelson dos Prazeres. As vogais médias pretônicas /e/ e lo/ no português falado na zona rural no Município de Mocajuba/NE do Pará. Cametá: UFPA/CUNTINS. 2013. (Trabalho de Conclusão de Curso)

ARAÚJO, Marivana; RODRIGUES, Doriedson. As vogais médias pré-tônicas /e/ e lo/no português falado no município de Cametá/Ne do Pará - uma abordagem variacionista. Universidade Federal do Pará, 2007.

BISOL, Leda. Harmonização vocálica: uma regra variável. Tese de Doutorado em Línguística e filologia apresentada à Faculdade de Letras da UFRJ. Rio de Janeiro. $1^{\circ}$ Semestre de 1981.

CAMPOS, B. M. S. Alteamento Vocálico em Posição Pretônica. 2008. (Dissertação de Mestrado). Belém: UFPA, 2008. (Dissertação de Mestrado)

CASSIQUE, Orlando. Menina Bunita Minina ... olhus esverdeados: estudo variacionista da nasalidade vocálica pré-tônica no português de Breves-Pará. 2001. Belém: UFPA, 2001. (Dissertação de Mestrado) 
COSTA, Raquel Maria da Silva. Descrição sociolinguística das vogais médias postônicas não-finais lo/ e lel no português falado no município de Cametá-PA. Belém - Pará: UFPA, 2010. (Dissertação de Mestrado).

DIAS, Marcelo; CASSIQUE, Orlando; CRUZ, Regina. O alteamento das vogais pré-tônicas no português falado na área rural do município de Breves, Pará: uma abordagem variacionista. Disponível em: // www.revel.inf.br/site2007/_pdf/9/artigos/. Acesso em 15 de setembro de 2020.

FREITAS, Simone Negrão de. As vogais médias pretônicas no falar da cidade de Bragança. 2001. Belém, UFPA, 2001. (Dissertação de Mestrado).

LABOV, William. The social motivation of a sound change. Word, n.19, p.273-309, 1963.

LABOV, William. Padrões sociolinguísticos. São Paulo: Parábola Editorial, 2008.

LABOV, William. Principles of linguistic change. Social Factors: volume 2. Massachusetts: Blackwell Publishers Inc., 2001.

MATTOSO CÂMARA JR. Joaquim. Estrutura da língua portuguesa. Rio de Janeiro: Vozes, 2011.

MORAES, Marlúcia Lopes. As vogais médias pretônicas le/ e /o/ no português falado na zona rural do Município de Cametá: uma caracterização acústica. Cametá: UFPA/CUNTINS. 2015. (Trabalho de Conclusão de Curso)

NASCENTES, Antenor (1964). O Idioma Nacional. Rio de Janeiro, Livraria Acadêmica, 1964.

OLIVEIRA, Daniele de Abreu; CRUZ, Regina. C. F. O. Alteamento das vogais prétônicas no português falado na área urbana do município de Breves-Pa: uma abordagem variacionista. In: Seminário Internacional de Fonologia, 2007b. Porto Alegre - RS: EDIPUCRS, 2007. v.1.

RODRIGUES, Doriedson do Socorro. Da zona urbana à rural/entre a tônica e a prétônica: alteamento /o/ > [u] no português falado no município de Cametá/Ne paraense - uma abordagem variacionista. Belém - Pará: UFPA, 2005. (Dissertação de Mestrado).

SILVA NETO, Serafim. Introdução ao estudo da Língua Portuguesa no Brasil. 4. ed. Rio de Janeiro: Presença, 1957.

WEINREICH, Uriel; LABOV, William; HERZOG Marvin I. (Tradução Marcos Bagno) Fundamentos empíricos para uma teoria da Mudança Linguística. Parábola Editorial. São Paulo: 2006. 